\title{
Development of model-based publication for scientific communication
}

\author{
Hugo Cornelis ${ }^{1}$, Allan D Coop ${ }^{2}$, James M Bower ${ }^{1 *}$ \\ From Nineteenth Annual Computational Neuroscience Meeting: CNS*2010 \\ San Antonio, TX, USA. 24-30 July 2010
}

We are developing a new set of computational tools to support the evaluation, understanding, sharing and publication of computational models of the nervous system. This is intended to lay the ground work for making models, rather than, as present, the written description of models, the base for scientific publication in neuroscience. The project is organized around ongoing research and development of the GENESIS modeling system. However, the publication system is designed to be platform independent as it adheres to the CBI federated software architecture [1].

\section{Methods}

The publication paradigm extends a previously reported user workflow that organizes the development, maintenance, and extension of modeling projects [2]. This publication workflow is managed from a user modifiable GUI that controls analysis, comparison, and peer reviewed electronic publication of computational models and simulation results. The GUI provides access to a model publication database that includes a structured narrative (Introduction, Methods, Results, Discussion), accounts for the micro-evolution of a model, while also giving a framework for exploration of the model as a tutorial. The GUI also automatically creates a project record by tracking all models, simulation configurations, and results of a given research project as well as maintaining a graph of ancestry during the lifetime of a model.

\section{Results}

A user will be able to select for publication the interesting parts of a project record that in their view represent the important outcomes of the modeling effort.
Operationally, the GUI contains a library of frames of reference populated by an investigator with reference to model history, including new results and observations. Manuscript submission pushes the complete graph of ancestry (including dead ends and reference frames) to an external database where it becomes available for review. The initial stage of review will be semi-automatic, determining, for example, the eccentricity of core model parameters. The peer-reviewer is then freed to focus on the frames of reference that validate a model as a precursor to the novel aspects of a project (including the narrative). Once published the system supports a wiki-like interactive discussion of a model and its results, and also makes the model available for modification and expansion. A macro-evolution tracking mechanism will track lineage across publications as a new form of attribution and impact measurement.

\section{Conclusions}

This publication paradigm provides a mechanism for the ordered evaluation, sharing, and evolution of "Community Models" of components and parts of the nervous system, including author attribution and lineage tracking.

\section{Acknowledgements}

Research supported by NIH grants 2 RO1 NS049288-5 and 3 R01 NS0492880651 to UTHSCSA.

\section{Author details}

${ }^{1}$ Department of Epidemiology and Biostatistics, University of Texas Health Sciences Center at San Antonio, San Antonio, TX 78229, USA. ${ }^{2}$ Research Imaging Institute, University of Texas Health Sciences Center at San Antonio, San Antonio, TX 78229, USA.

Published: 20 July 2010

* Correspondence: bower@uthscsa.edu

${ }^{1}$ Department of Epidemiology and Biostatistics, University of Texas Health Sciences Center at San Antonio, San Antonio, TX 78229, USA 


\section{References}

1. Cornelis H, Edwards M, Coop AD, Bower JM: The CBI architecture for computational simulation of realistic neurons and circuits in the GENESIS 3 software federation. BMC Neurosci 2008, 9(S1):88.

2. Coop $A D$, Cornelis $H$, Rodriguez M, Bower JM: Using GENESIS 3 for single neuron modeling. BMC Neurosci 2009, 10(S1):52.

\section{doi:10.1186/1471-2202-11-S1-P69}

Cite this article as: Cornelis et al:: Development of model-based publication for scientific communication. BMC Neuroscience 2010 11(Suppl 1):P69.

Submit your next manuscript to BioMed Central and take full advantage of:

- Convenient online submission

- Thorough peer review

- No space constraints or color figure charges

- Immediate publication on acceptance

- Inclusion in PubMed, CAS, Scopus and Google Scholar

- Research which is freely available for redistribution

Submit your manuscript at www.biomedcentral.com/submit
C Biomed Central 